Check for updates

Cite this: RSC Adv., 2017, 7, 40711

\title{
Detoxification of organophosphates using imidazole-coated Ag, Au and AgAu nanoparticles $\dagger$
}

Received 25th June 2017

Accepted 11th August 2017

DOI: $10.1039 / c 7 r a 07059 d$

rsc.li/rsc-advances

\author{
Valmir B. Silva, ${ }^{a}$ Thenner S. Rodrigues, (DD ${ }^{\mathrm{b}}$ Pedro H. C. Camargo (DD ${ }^{\mathrm{b}}$ \\ and Elisa S. Orth (D)*a
}

Organophosphate (OP) detoxification is a worldwide problem due to the high stability of $\mathrm{P}-\mathrm{O}$ bonds. Here, we designed several imidazole-coated nanocatalysts targeted towards the cleavage of OP and thus their detoxification. Specifically, $\mathrm{Ag}, \mathrm{Au}$ and bimetallic $\mathrm{AgAu}$ nanoparticles (NPs) supported on $\mathrm{SiO}_{2}$ were functionalized with methimazole (MTZ), which comprises thiol and imidazole groups, foreseeing enabling freely available imidazole groups. Raman analyses indicate that MTZ interacts preferably via its sulfur atom over Au NPs and via the nitrogen of the imidazole ring over Ag NPs. The MTZ-derived nanocatalysts were effective towards OP cleavage. For instance, rate enhancements of $10^{8}$ fold were obtained for the toxic pesticide Paraoxon, compared to the uncatalyzed reaction. Interestingly, Auderived nanocatalysts were significantly more effective since the imidazole group is free to react with the $\mathrm{OP}$, which is not possible when $\mathrm{Ag}-\mathrm{N}$ interactions take place.

\section{Introduction}

Organophosphates (OP) are intrinsically related to many fundamental biological functions, such as biosynthesis, signaling, regulation, and energy transduction. ${ }^{\mathbf{1}}$ Moreover, they are responsible for the preservation of genetic information since they constitute DNA and RNA strands. ${ }^{2}$ Actually, one-third of all biological proteins are phosphorylated at some time, evidencing the importance of phosphoryl transfer. OP are mostly known for their high stability. ${ }^{3}$ For example, the hydrolysis of DNA is estimated take in over 100000 years. ${ }^{4}$ Since enzymes are very successful in promoting phosphorylation in biological systems, ${ }^{2}$ they have bioinspired many mimicking studies. The downside of OP's stability is that they have been used as a scaffold for many chemical warfare and pesticides (Scheme 1), knowingly to have high toxicity, sometimes even being lethal. ${ }^{5}$ Not surprising, much effort has been directed towards the development of efficient methods of destruction and detection of these toxic OP, focusing on deactivating unused (probably prohibited) stockpiles and monitoring abusive use of agrochemical and/or chemical attacks ${ }^{5,6}$

It is noteworthy that poisoning by pesticides is a serious worldwide public concern. ${ }^{7}$ As a matter of security, many studies in this field have used structural mimics of pesticides and chemical warfare that usually have lower toxicity and higher reactivity so that

${ }^{a}$ Departamento de Quimica, Universidade Federal do Paraná, CP 19032, 81531-980 Curitiba, PR, Brazil. E-mail: elisaorth@ufpr.br

${ }^{b}$ Instituto de Química, Departamento de Química Fundamental, Universidade de São Paulo, Av. Prof. Lineu Prestes 748, SP 05508-900, São Paulo, Brazil

$\dagger$ Electronic supplementary information (ESI) available. See DOI: 10.1039/c7ra07059d the reaction can be feasibly followed. For example, dimethyl methylphosphonate (DMMP), $p$-nitrophenyl diphenylphosphate (PNPDPP) ${ }^{5}$ and diethyl-2,4-dinitrophenyl phosphate (DEDNPP) $)^{\mathbf{8 - 1 0}}$ have been explored, as shown in Scheme 1.

In order to pursue the detoxification of OP, many bioinspired models have been proposed as detoxifying agent or artificial enzymes targeting the phosphoryl cleavage. ${ }^{5}$ In this context, imidazole-derived catalysts have attracted great

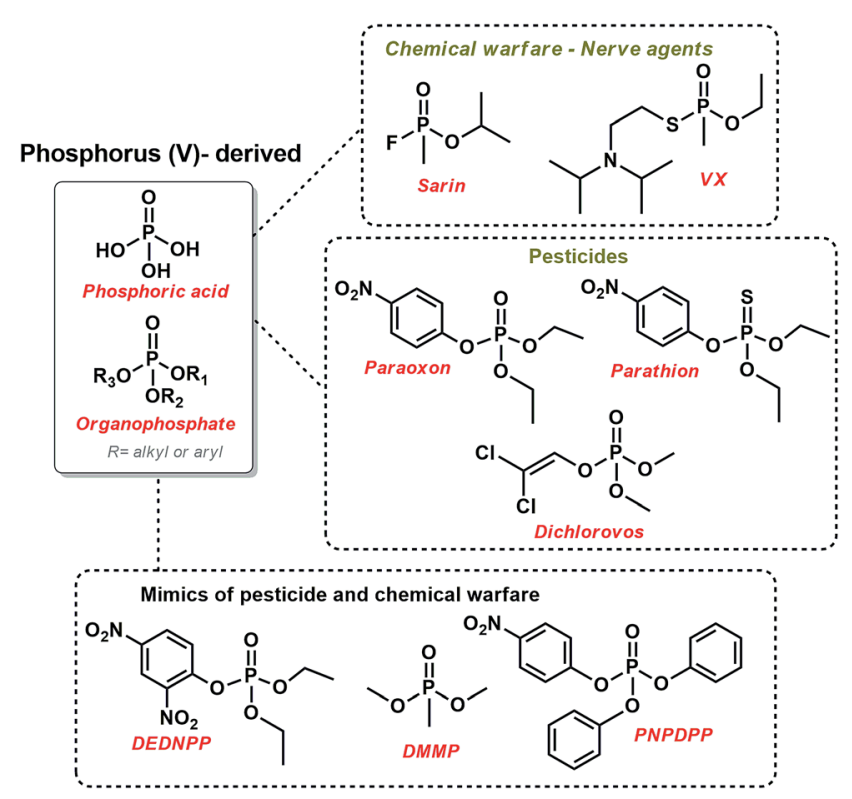

Scheme 1 The structure of some relevant organophosphates used as chemical warfare and pesticides, along with some mimics of toxic OP. 


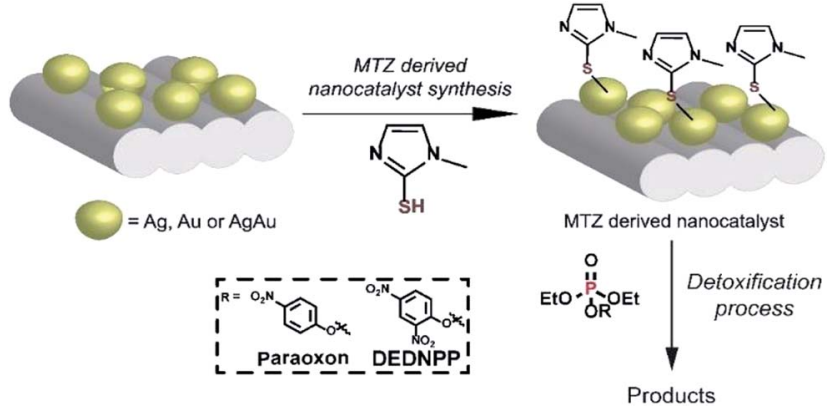

Fig. 1 Functionalization of $\mathrm{AuSiO}_{2}, \mathrm{AgSiO}_{2}$ or $\mathrm{AgAuSiO}_{2}$ with $\mathrm{MTZ}$.

attention due to their presence in many enzymatic active sites and their chemical versatility, ${ }^{\mathbf{1 1}}$ i.e., they can react as acid-base or nucleophilic catalysts under considerably mild conditions $(\mathrm{pH} \sim 7) .{ }^{\mathbf{1 2 , 1 3}}$ Another promising class of catalysts for $\mathbf{O P}$ cleavage involve nanoparticles (NPs), ${ }^{14}$ although there are still only a few reports in this field,,$^{5,15-20}$ in contrast to the many studies regarding NPs-based sensors for various OP. ${ }^{21}$

The physicochemical features of several NPs, such as shape and size, can be decisive for catalysis. ${ }^{2-24} \mathrm{~A}$ previous study showed that the reduction of 4-nitrophenol can be catalyzed by $\mathrm{Ag}$ and $\mathrm{AgAu}$ NPs alone, with higher reactivity for the later attributed to $\mathrm{Au}$ content and the increased surface area due to the hollow interiors. ${ }^{25}$ In another study, bimetallic nanoshells of AgAu, AgPd, and AgPt NPs were used as bio-metallo catalysts with dual activity for transesterification; and silane oxidation. ${ }^{26}$ Insofar, to the best of our knowledge, there are no studies correlating NPs features with its effect on OP degradation.

Herein, we coated silver $\left(\mathbf{A g S i O}{ }_{2}\right)$, gold $\left(\mathbf{A u S i O} \mathbf{O}_{2}\right)$ and bimetallic nanoshells $\mathbf{A g A u S i O}{ }_{2}$ NPs (supported on $\mathrm{SiO}_{2}$ ) with a thiolsubstituted imidazole (methimazole, MTZ) in order to obtain nanocatalysts with freely available imidazole moieties. We choose MTZ due to the extraordinary catalytic activity known for imidazole groups (vide supra) and the thiol group that interacts favorably with NPs, ${ }^{20,27}$ hence anchoring efficiently imidazole moieties on the NPs surface. For this purpose, the NPs were firstly obtained with controlled shape and size following a previously reported procedure. ${ }^{28,29}$ Then, the NPs were functionalized with MTZ (Fig. 1). Finally, the nanocatalysts were evaluated toward OP degradation, using the simulant DEDNPP and the pesticide Paraoxon as model substrates.

\section{Experimental}

\section{Materials}

MTZ Analytical grade silver nitrate $\left(\mathrm{AgNO}_{3}, 99 \%\right.$, Sigma-Aldrich), polyvinylpyrrolidone (PVP, Sigma-Aldrich, M.W. $10000 \mathrm{~g} \mathrm{~mol}^{-1}$ ), polyvinylpyrrolidone (PVP, Sigma-Aldrich, M.W. $55000 \mathrm{~g} \mathrm{~mol}^{-1}$ ), ethylene glycol (EG, 99.8\%, Sigma-Aldrich), tetrachloroauric(III) acid trihydrate $\left(\mathrm{HAuCl}_{4} \cdot 3 \mathrm{H}_{2} \mathrm{O}, \geq 99.9 \%\right.$, Sigma-Aldrich), silica (pore size $22 \AA, 800 \mathrm{~m}^{2} \mathrm{~g}^{-1}$, CAS number 112926-00-8, SigmaAldrich), ethanol (Êxodo) were used as received.

\section{Synthesis of $\mathrm{Ag} \mathrm{NPs}{ }^{29}$}

Ag seeds were prepared by the polyol process. In a typical experiment, $5 \mathrm{~g}$ of polyvinylpyrrolidone (PVP, $10000 \mathrm{~g} \mathrm{~mol}^{-1}$ ) was dissolved in $37.5 \mathrm{~mL}$ of ethylene glycol. Then, $\mathrm{AgNO}_{3}$ (200 $\mathrm{mg}, 1.2 \mathrm{mmol}$ ) was added and mixed until the complete dissolution. The resulting solution was heated to $125{ }^{\circ} \mathrm{C}$ for 2.5 hours, leading to the appearance of a greenish-yellow color, allowed to cool down to room temperature, and diluted to 125 $\mathrm{mL}$ of water. After this step, $46 \mathrm{~mL}$ of the resulting suspension $\left(0.2197 \mathrm{mg} \mathrm{mL} \mathrm{m}^{-1}\right.$, determined by ICP) were washed twice with ethanol and three times with water by successive rounds of centrifugation at $15000 \mathrm{rpm}$ and removal of the supernatant. After washing, the product was suspended in $10 \mathrm{~mL}$ of deionized water.

\section{Synthesis of Au NPs ${ }^{30}$}

The synthesis of $\mathrm{Au}$ nanospheres was performed by a seeded growth approach. In the first step, Au seeds were synthesized by adding $150 \mathrm{~mL}$ of a $2.2 \mathrm{mmol} \mathrm{L}^{-1}$ sodium citrate aqueous solution to a $250 \mathrm{~mL}$ round-bottom flask under magnetic stirring. This system was heated to $100{ }^{\circ} \mathrm{C}$ for 15 minutes. Then, 1 $\mathrm{mL}$ of a $25 \mathrm{mmol} \mathrm{L}^{-1} \mathrm{AuCl}_{4}{ }^{-}$(aq) solution was added, and the reaction mixture was kept at $100{ }^{\circ} \mathrm{C}$ under vigorous stirring for 30 minutes. The obtained Au nanoparticles were employed as seeds for the synthesis of Au NPs having larger sizes by two successive steps of Au deposition. For the first deposition step, 1 $\mathrm{mL}$ of a $60 \mathrm{mmol} \mathrm{L}^{-1}$ sodium citrate solution was added to the same $250 \mathrm{~mL}$ round-bottom flask containing the Au NPs seeds under magnetic stirring at $100{ }^{\circ} \mathrm{C}$ for 5 minutes. Afterward, 1 $\mathrm{mL}$ of a $25 \mathrm{mmol} \mathrm{L}^{-1} \mathrm{AuCl}_{4}{ }^{-}$(aq) solution was added to the reaction mixture containing the Au NPs seeds and the reaction mixture was carried out for another $30 \mathrm{~min}$. Similarly, a second deposition step could be performed by adding another $1 \mathrm{~mL}$ of a $60 \mathrm{mmol} \mathrm{L}{ }^{-1}$ sodium citrate solution and $1 \mathrm{~mL}$ of a $25 \mathrm{mmol}$ $\mathrm{L}^{-1} \mathrm{AuCl}_{4}{ }^{-}$(aq) solution to the reaction mixture obtained after the first deposition step, in which the Au NPs produced after the first deposition step served as seeds for further growth. After the reaction, the resulting suspension was allowed to cool down to room temperature. After this step, $88 \mathrm{~mL}$ of the resulting suspension ( $0.1146 \mathrm{mg} \mathrm{mL}^{-1}$, determined by ICP) were washed three times with water by successive rounds of centrifugation at $15000 \mathrm{rpm}$ and removal of the supernatant. After washing, the product was suspended in $10 \mathrm{~mL}$ of deionized water.

\section{Synthesis of AgAu nanoshells ${ }^{29}$}

The synthesis of AgAu nanoshells was based on the galvanic replacement reaction between $\mathrm{Ag}$ nanospheres and $\mathrm{AuCl}_{4}{ }^{-}$(aq). In a typical procedure, a mixture containing $50 \mathrm{~mL}$ of PVP aqueous solution $\left(0.1 \mathrm{wt} \%\right.$, M.W. $\left.55000 \mathrm{~g} \mathrm{~mol}^{-1}\right)$ and $10 \mathrm{~mL}$ of the as-prepared suspension containing the $\mathrm{Ag}$ nanospheres was stirred at $100{ }^{\circ} \mathrm{C}$ for $10 \mathrm{~min}$ in a $250 \mathrm{~mL}$ round-bottom flask. Then, $20 \mathrm{~mL}$ of $\mathrm{AuCl}_{4}{ }^{-}$(aq) $\left(0.6 \mathrm{mmol} \mathrm{L}^{-1}\right)$ was added dropwise and the reaction allowed to proceed at $100{ }^{\circ} \mathrm{C}$ for another $1 \mathrm{~h}$. After that, the suspension was allowed to cool down to room temperature and $28 \mathrm{~mL}\left(0.0458 \mathrm{mg} \mathrm{mL}^{-1}\right.$, determined by ICP) 
were washed twice with a supersaturated $\mathrm{NaCl}$ solution and three times with water by successive rounds of centrifugation at $15000 \mathrm{rpm}$ and removal of the supernatant. After washing, the product was suspended in $10 \mathrm{~mL}$ of deionized water.

\section{Synthesis of the $\mathrm{SiO}_{2}$ supported $\mathrm{NPs}^{28}$}

The incorporation of $\mathrm{Ag}, \mathrm{Au}$, and $\mathrm{AgAu}$ nanostructures onto a silica matrix (1\% wt, metal basis) were performed based on a wet impregnation approach. In a typical run, $10 \mathrm{~mL}$ of the suspensions containing the respective nanoparticles washed and concentrated were added dropwise to a beaker containing $1 \mathrm{~g}$ of commercial silica suspended in $20 \mathrm{~mL}$ of deionized water under magnetic stirring. The resulting mixture was stirred at room temperature for $24 \mathrm{~h}$. After this step, the resulting suspensions were washed three times with distilled water and twice with ethanol by successive rounds of centrifugation at $7000 \mathrm{rpm}$ and removal of the supernatant. The resulting catalysts were then treated at $120^{\circ} \mathrm{C}$ for $2 \mathrm{~h}$ under air.

\section{Coating of the NPs with MTZ}

The MTZ derived nanocatalysts were prepared as follows: $500 \mathrm{mg}$ of the $\mathrm{SiO}_{2}$ supported $\mathbf{A g S i O}_{2}, \mathbf{A u S i O}_{2}$ or $\mathbf{A g A u S i O}{ }_{2} \mathrm{NPs}$ was added to a becker along with MTZ (26.0, 15.0 and $21.0 \mathrm{mg}$

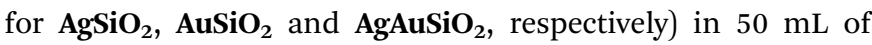
ethanol. The mixture was stirred during $24 \mathrm{~h}$ followed by centrifugation (12 $000 \mathrm{rpm}$ ) and separated. In the following, the material was washed with ethanol (three times), centrifugated, and the supernatant was discarded. The ethanol was evaporated at room temperature. The samples were denominated $\mathbf{A g S i O}_{2}-$ $\mathbf{M T Z}, \mathbf{A u S i O}_{2}-\mathbf{M T Z}$ and $\mathbf{A g A u S i O}_{2}-\mathbf{M T Z}$, originated from $\mathbf{A g S i O}_{2}, \mathbf{A u S i O}_{2}$, and $\mathbf{A g A u S i O}_{2}$ NPs, respectively.

\section{Characterizations}

For the NPs, the scanning electron microscopy (SEM) images were obtained using a JEOL field emission gun electron microscope JSM6330F operated at $5 \mathrm{kV}$. The samples were prepared by drop-casting an aqueous suspension containing the nanostructures over a silicon wafer, followed by drying under ambient conditions. Transmission electron microscopy (TEM) images were obtained with a JEOL JEM1010 microscope operated at $80 \mathrm{kV}$. Samples for TEM were prepared by dropcasting an aqueous suspension of the nanostructures over a carbon-coated copper grid, followed by drying under ambient conditions. UV-vis spectra were obtained from aqueous suspensions containing the nanostructures with a Shimadzu $\mathrm{UV}-1700$ spectrophotometer. The $\mathrm{Ag}$ and $\mathrm{Au}$ atomic percentages were measured by inductively coupled plasma optical emission spectrometry (ICP-OES) using a Spectro Arcos equipment. The X-ray diffraction (XRD) data were obtained using a RigakuMiniflex equipment, $\mathrm{CuK} \alpha$ radiation. The diffraction pattern was measured in the range of $10-90^{\circ} 2 \theta$ with a $1^{\circ} \mathrm{min}^{-1}$ angular speed scan. For the MTZ-derived NPs, Raman spectra were obtained with a Renishaw spectrophotometer using the $632.8 \mathrm{~nm}$ excitation laser, with 25 accumulations and $25-50 \%$ of the laser intensity.

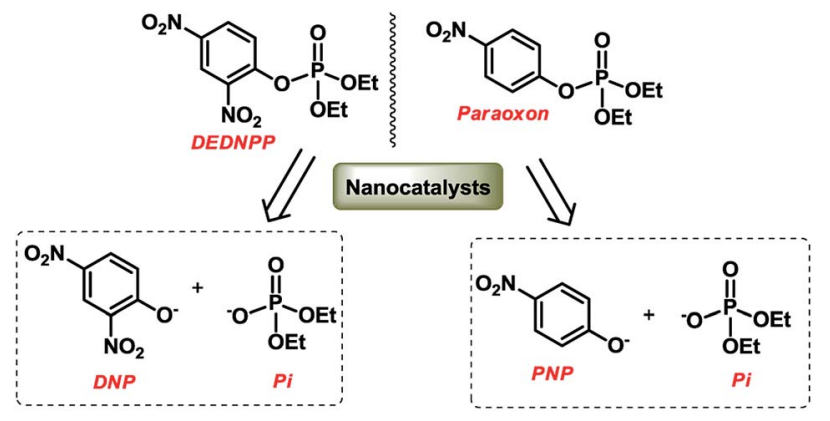

Scheme 2 Cleavage reaction of DEDNPP and Paraoxon in the presence of the nanocatalysts.

\section{Catalytic studies of OP detoxification}

For the catalytic studies, two OP were employed: DEDNPP and Paraoxon. Pseudo-first order conditions were maintained, where $30 \mathrm{mg}$ of MTZ-derived nanocatalyst was added to $3 \mathrm{~mL}$ of a buffered solution (bicarbonate $0.2 \mathrm{~mol} \mathrm{~L}^{-1}$ ). The reaction started upon addition of $15 \mu \mathrm{L}$ of DEDNPP or Paraoxon stock solution $\left(5 \times 10^{-3} \mathrm{~mol} \mathrm{~L}^{-1}\right.$ in acetonitrile) and the medium was maintained under magnetic stirring ( $4 \mathrm{~h}$ and 15 days for DEDNPP and Paraoxon, respectively). The suspension was centrifugated (12000 rpm) and UV-vis spectra of the supernatant were recorded. The catalytic activity was calculated based on the product concentration, hence OP degradation by measuring the absorbance variation at $400 \mathrm{~nm}$ related to the products 4-nitrophenolate (PNP) or 2,4 dinitrophenolate (DNP), that originated from Paraoxon and DEDNPP, respectively (Scheme 2). The molar absorptivity $(\varepsilon)$ used were 18380 and $12100 \mathrm{~L} \mathrm{~mol}^{-1} \mathrm{~cm}^{-1}$ for PNP and DNP, respectively. ${ }^{31,32}$ Considering pseudo-first order kinetics, already corroborated for these reactions in a separate study, the integrated rate law was used to obtain the pseudo-first order constant.
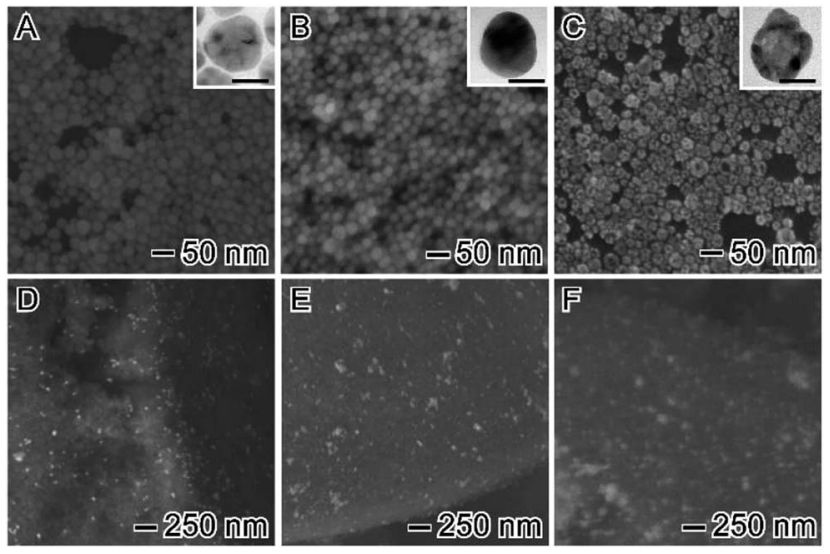

Fig. 2 (A-C) SEM images of Ag nanospheres (A), Au nanospheres (B), and $\mathrm{AgAu}$ nanoshells $(\mathrm{C})$. The insets correspond to their corresponding TEM images (the scale bars in the insets correspond to $20 \mathrm{~nm}$ ). (D-F) SEM images of (D) $\mathrm{AgSiO}_{2}$, (E) $\mathrm{AuSiO}_{2}$, and (F) $\mathrm{AgAuSiO}_{2}$ materials that were obtained from wet impregnation of the samples $(A-C)$ onto a commercial $\mathrm{SiO}_{2}$ support. 


\section{Results and discussion}

\section{Characterization of the $\mathrm{SiO}_{2}$ supported NPs}

Our studies started with the synthesis of $\mathrm{Ag}$ nanospheres, $\mathrm{Au}$ nanospheres, and AgAu nanoshells as shown in Fig. 2A-C, respectively. $\mathrm{Ag}$ nanospheres (Fig. $2 \mathrm{~A}$ ) were obtained by a onestep polyol approach and were $35 \pm 4 \mathrm{~nm}$ in diameter. ${ }^{33}$ On the other hand, Au nanospheres (Fig. 2B) were obtained by a seeded growth approach, in which $\mathrm{Au}$ nanospheres obtained by citrate reduction of $\mathrm{AuCl}_{4}{ }^{-}(\mathrm{aq})$ acted as template for additional $\mathrm{Au}$ deposition and growth leading to the formation of nanoparticles displaying larger diameters $(36 \pm 3 \mathrm{~nm})$ that were similar to the $\mathrm{Ag}$ nanospheres. ${ }^{30}$ For the AgAu nanoshells, the obtained $\mathrm{Ag}$ nanospheres were employed as sacrificial templates in the galvanic replacement reaction using $\mathrm{AuCl}_{4}$ - (aq), which represents an effective strategy for the synthesis of hollow nanostructures displaying controllable properties in a single-step. ${ }^{29,34}$ As depicted in Fig. 2C, the formation of the hollow interiors is confirmed by the brighter mass-thickness contrast at the center of the AgAu nanoshells, which were 36 $\pm 4 \mathrm{~nm}$ in diameter, in agreement with the use of $\mathrm{Ag}$ nanospheres as templates. Interestingly, all obtained nanostructures displayed spherical shapes and relatively monodisperse sizes, which allowed us systematically investigate their catalytic performances as a function of the compositions and structures. The metal at $\%$ in the nanostructures were determined by ICPOES analyses and corresponded to $100 \%$ of $\mathrm{Ag}, 100 \%$ of $\mathrm{Au}$, and $49 \%$ of $\mathrm{Ag}+51 \%$ of $\mathrm{Au}$ for $\mathrm{Ag}, \mathrm{Au}$, and $\mathrm{AgAu}$, respectively.

After the synthesis of the Ag, Au, and AgAu nanostructures, we turned our attention to their incorporation onto the surface of a commercial $\mathrm{SiO}_{2}$ in order to produce powdered catalysts, which are strongly desired in terms of heterogeneous catalysis due to their relatively easy separation, purification, and reuse. In addition, the uniform incorporation of NPs over solid supports have also been demonstrated as a promising strategy to prevent the particle agglomeration during the catalytic processes. ${ }^{28}$ Fig. $2 \mathrm{D}-\mathrm{F}$ show SEM images for the produced catalysts after the NPS incorporation onto the $\mathrm{SiO}_{2}$ support. Interestingly, for all nanomaterials, an excellent dispersion of metal constituents was

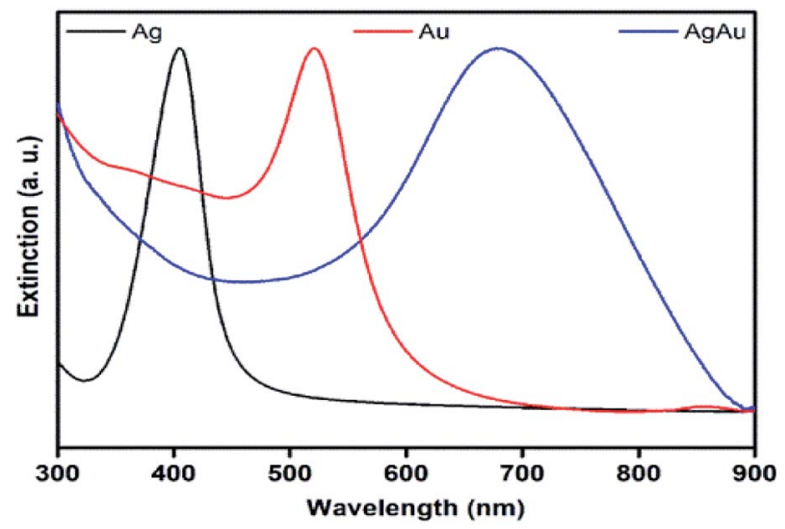

Fig. 3 UV-vis extinction spectra recorded from aqueous suspensions containing Ag nanospheres (black trace), Au nanospheres (red trace), and AgAu nanoshells (blue trace).

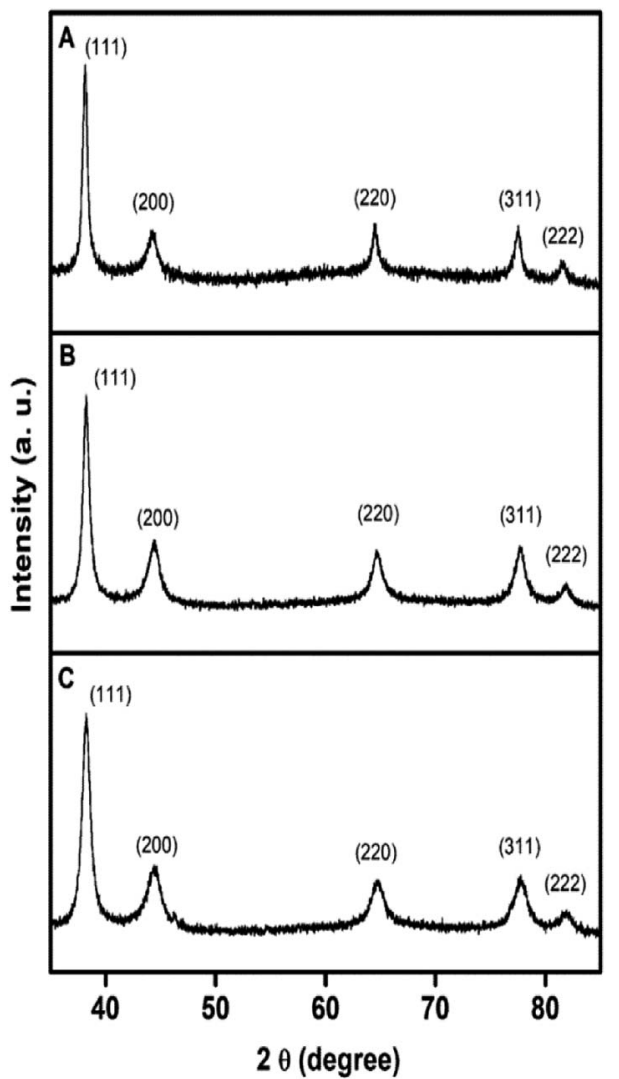

Fig. 4 XRD profiles of (A) Ag nanospheres, (B) Au nanospheres, and (C) AgAu nanoshells.

observed over the entire $\mathrm{SiO}_{2}$ surface and no significant agglomeration and changes on the morphologies were detected, indicating the robustness of our employed wet impregnation method to produce solid metal/ $\mathrm{SiO}_{2}$ catalysts. Here, the metal loading corresponded to $1 \mathrm{wt} \%$ (Fig. 2F). The solid catalysts were

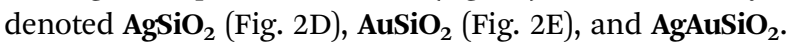

Fig. 3 shows the UV-vis extinction spectra for the obtained $\mathrm{Ag}$ and $\mathrm{Au}$ nanospheres and $\mathrm{AgAu}$ nanoshells. The $\mathrm{Ag}$ and $\mathrm{Au}$ nanospheres displayed clear extinction peaks centered at $\approx 410$ and $520 \mathrm{~nm}$ assigned to the dipolar mode of their surface plasmon resonance excitation ${ }^{29,30}$ On the other hand, a red-shift and broadening of the SPR in the AgAu nanoshells was observed compared to the Ag nanospheres employed as templates. This behavior can be associated with the Au deposition as well as the formation of the hollow interiors in during the galvanic reaction. ${ }^{25}$

The formation of $\mathrm{Ag}, \mathrm{Au}$, and $\mathrm{AgAu}$ was also monitored by XRD analyses (Fig. 4), in which the XRD patterns also confirmed the formation of Ag (Fig. 4A), Au (Fig. 4B) and AgAu (Fig. 4C) nanostructures without the presence of any significant crystalline impurities. However, as both $\mathrm{Ag}$ and Au has very similar lattice constants, the XRD diffraction peaks for these two species could not be resolved under our experimental conditions.

\section{Characterization of the MTZ-derived NPs coated material}

Regarding the MTZ-derived NPs, to the best of our knowledge, this represents the first report using MTZ on NPs supported on 
<smiles>Cn1ccnc1S</smiles>

Thiol
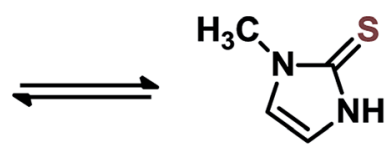

Thione
Scheme 3 Tautomeric equilibrium for MTZ

$\mathrm{SiO}_{2}$. There are other studies that report other thiol-substituted imidazole for coating NPs, evidencing that the thiol group interacts with the NPs, enabling freely available imidazole moieties. For example, in a previous study, authors report a dipeptide-functionalized thiol with terminal histidine and carboxylate groups that was used to passivate Au NPs. The material was successfully prepared and used as catalysts in acyl transfer reactions, although the NPs nature was not the focus of study. ${ }^{27}$ In another report, $\mathrm{N}$-methylimidazole derivative functionalized Au NPs were obtained similarly via thiol anchoring on NPs surface, which afterward was employed in the cleavage of 2,4-dinitrophenyl acetate. ${ }^{20}$ It is noteworthy, that we also attempted to anchor MTZ on NPs (Ag, Au, and AgAu) not supported on $\mathrm{SiO}_{2}$, but functionalization was followed by aggregation of the particles.

MTZ is a known drug (commercially Tapazol) used for the treatment of hyperthyroidism..$^{35}$ MTZ has a tautomeric equilibrium of thiol-thione as shown in Scheme 3. The concentration of each species depends on the $\mathrm{pH}$, although in general, the thione species predominates. For example, at $\mathrm{pH} 9$, the percentage of thione is $65 \%{ }^{36}$ Another important feature of MTZ is its $\mathrm{p} K_{\mathrm{a}}$ of $11.38 .^{35}$

The MTZ-derived NPs were characterized by Raman spectroscopy. Indeed, Raman analysis of MTZ is quite difficult due to its tautomeric and ionic equilibrium, but overall results evidence that the NPs were successfully functionalized. Raman spectra are presented in Fig. 5 including spectrum of pure MTZ for comparison and additionally all spectra all plotted together in Fig. S1. $\dagger$ The Raman spectra for the NPs prior to the MTZ functionalization (red trace on Fig. 5) show bands that were characteristic of PVP (in the case of $\mathbf{A g S i O}_{2}$ and $\mathbf{A g A u S i O}{ }_{2}$ ), citrate (in the case of $\mathbf{A u S i O}_{2}$ ) and $\mathrm{SiO}_{2}$ (spectra for pure $\mathrm{SiO}_{2}$ and PVP are shown in the ESI $\dagger$ ). ${ }^{37,38}$ These species are present at the surface of the NPs as they were employed as stabilizers during the synthesis of each respective material. It is important to note that all the nanoparticles were washed by successive rounds of centrifugation and removal of the supernatant after their synthesis and isolation, material. Although this process removes the reducing agents, unreacted precursors, and the excess of stabilizers that are employed during the synthesis, stabilizer molecules remain at the surface of the NPs. Their detection in the Raman experiments is due to the surfaceenhanced Raman scattering (SERS) effect as enabled by Ag, $\mathrm{Au}$, and AgAu NPs.

Upon functionalization $\left(\mathbf{A g A u S i O}_{2}-\mathbf{M T Z}, \mathbf{A g S i O}_{2}-\mathbf{M T Z}\right.$ and $\mathbf{A u S i O}_{2}-\mathbf{M T Z}$ in Fig. 5) it is possible identify some characteristic bands of MTZ that are identified in the first spectrum: $:^{17,35,36}(\mathrm{i})$ at
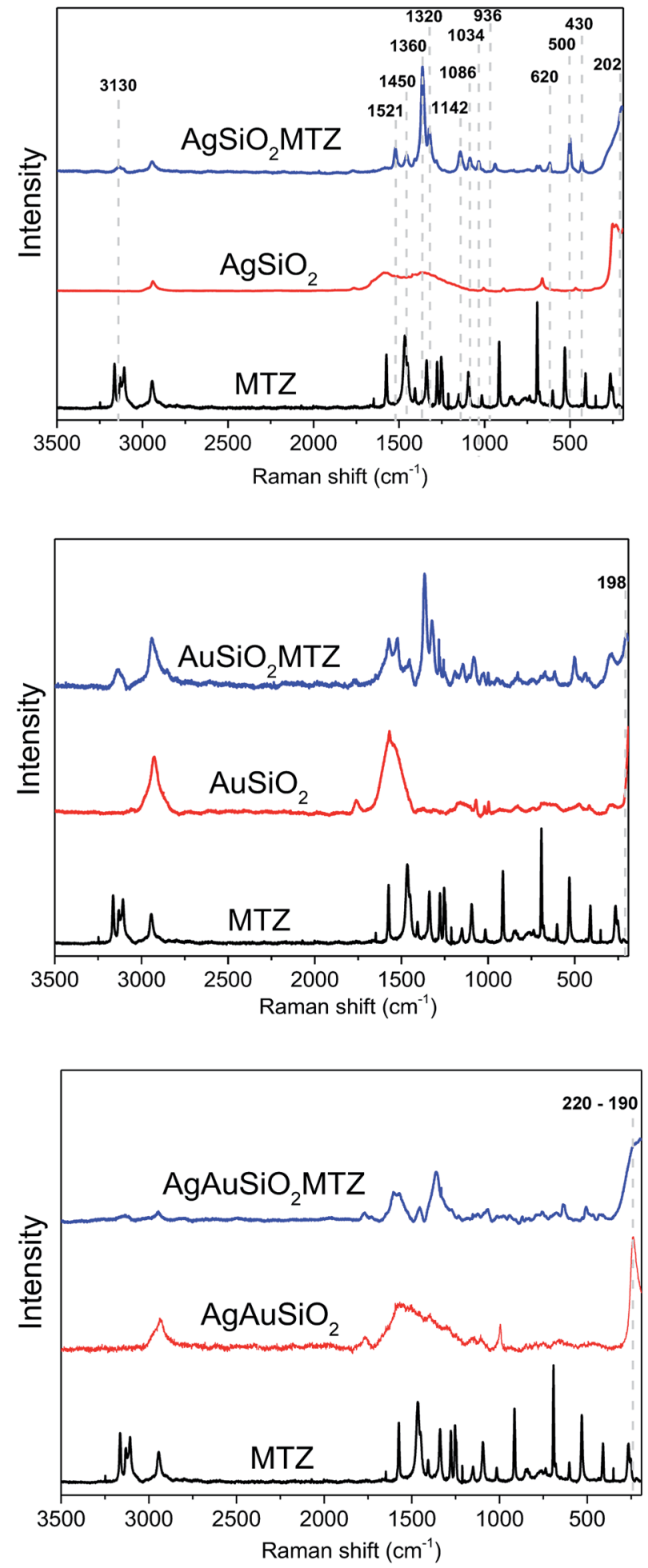

Fig. 5 Ordinary Raman and SERS spectra $(l=632.8 \mathrm{~nm})$ for pure MTZ, bare NPs, and MTZ-functionalized Ag, Au and AgAu NPs.

$3130 \mathrm{~cm}^{-1}$ due to ring $\mathrm{C}-\mathrm{H}$ stretching; (ii) at $1521 \mathrm{~cm}^{-1}$ due to $\mathrm{C}-\mathrm{C}$ and $\mathrm{C}-\mathrm{N}$ stretching, along with ring $\mathrm{C}-\mathrm{H}$ bending; (iii) at $1450 \mathrm{~cm}^{-1}$ attributed to $\mathrm{C}-\mathrm{S}$ and ring $\mathrm{C}-\mathrm{N}$ stretching, in addition to ring $\mathrm{C}-\mathrm{H}$ bending; (iv) at $1360 \mathrm{~cm}^{-1}$ (most intense band) referent to $\mathrm{C}-\mathrm{N}$ ring stretching with contribution of $\mathrm{C}-\mathrm{H}$ 
bending; (v) at $1320 \mathrm{~cm}^{-1}$ attributed to ring $\mathrm{C}-\mathrm{N}$ stretching, ring bending and ring $\mathrm{CH}-\mathrm{NH}$ bending; (vi) $1142 \mathrm{~cm}^{-1}$ referent to $\mathrm{C}-\mathrm{S}$ and ring $\mathrm{C}-\mathrm{N}$ stretching, along with ring $\mathrm{C}-\mathrm{H}$ bending; (vii) at $1086 \mathrm{~cm}^{-1}$ due to ring $\mathrm{C}-\mathrm{N}$ stretching and ring $\mathrm{C}-\mathrm{H}$ bending; (viii) at $1034 \mathrm{~cm}^{-1}$ attributed to ring bending, ring $\mathrm{C}-\mathrm{H}$ bending, methylene $\mathrm{C}-\mathrm{H}$ bending (ix) at $936 \mathrm{~cm}^{-1}$ referent to ring bending, ring $\mathrm{C}-\mathrm{N}$ stretching and ring $\mathrm{CH}-\mathrm{NH}$ bending; ( $\mathrm{x}$ ) at $620 \mathrm{~cm}^{-1}$ due to out-of-plane ring and $\mathrm{CH}-\mathrm{NH}$ bending; (xi) at 500 and $430 \mathrm{~cm}^{-1}$ due to out-of-plane ring bending. It is noticeable that spectrum for pure MTZ presents more bands than discussed above and in addition some bands of MTZ are shifted when comparing coated materials to pure MTZ. Actually, these detected differences for the SERS spectra from the functionalized materials and ordinary Raman from pure MTZ are characteristic of many molecules and indicate that the functionalization was successful as previously observed. ${ }^{35,36,39}$ Moreover, the bands observed herein indicate that MTZ is present as thione and thiol/thiolate, ${ }^{35,36}$ although it should be noted that despite the high $\mathrm{p} K_{\mathrm{a}}$ for MTZ, previous studies show that the thiolate species is preferable for interacting with $\mathrm{Ag}$ and Au NPs. ${ }^{35}$

Regarding the nature of the interaction between NPs and MTZ, previous studies report that MTZ interacts with Au NPs preferably via the thiol group..$^{35}$ On the other hand, with Ag NPs, there are some reports that claim a preferable interaction via the nitrogen atom of the imidazole group,$^{36}$ although another study evidences that Ag NPs can also interact with thiol group ${ }^{35}$ or with both groups concomitantly. ${ }^{39}$ In fact, when analyzing Raman spectrum for $\mathbf{A u S i O}_{2}-\mathbf{M T Z}$, there is a band at $198 \mathrm{~cm}^{-1}$, not present in the non-coated material. Despite the typical bands of $\mathrm{SiO}_{2}$ in this region, they don't seem to overlap. This new band has been attributed in the literature to $\mathrm{Au}-\mathrm{S}$ stretching, indicating that for this material, MTZ interacts preferably via the thiolate group. ${ }^{35}$ In the case of $\mathbf{A g S i O}_{2}-\mathbf{M T Z}$, the band at $202 \mathrm{~cm}^{-1}$, inexistent without MTZ, can be attributed to $\mathrm{Ag}-\mathrm{N}$ stretching, ${ }^{36}$ indicating that for this material $\mathbf{M T Z}$ interacts preferably via the imidazole ring through the lone pair of the nitrogen atom. Finally, for $\mathbf{A g A u S i O}_{2}-\mathbf{M T Z}$, the spectrum is noisier, with a broad band in the region of $220-190 \mathrm{~cm}^{-1}$ that could be attributed to both $\mathrm{Ag}-\mathrm{S}$ and $\mathrm{Au}-\mathrm{N}$ interactions.

It should be noted that despite the similarities in the bands attributed to $\mathrm{Au}-\mathrm{S}$ and $\mathrm{Ag}-\mathrm{N}$, the other possible interactions $\mathrm{Au}-\mathrm{N}$ and $\mathrm{Ag}-\mathrm{S}$ are known to occur at higher wavenumbers $(\mathrm{Au}-$ $\mathrm{N} \sim 225 \mathrm{~cm}^{-1}$ and $\left.\mathrm{Ag}-\mathrm{S} \sim 240 \mathrm{~cm}^{-1}\right){ }^{40,41}$ Taken together, Raman analysis confirms that MTZ was anchored on the NPs and that for $\mathbf{A u S i O}_{2}-\mathbf{M T Z}$ the interaction seems to occur through the imidazole ring $(\mathbf{A g}-\mathrm{N})$. For $\mathbf{A g S i O}_{2}-\mathbf{M T Z}$, this occurs via the thiolate group (Au-S). For $\mathbf{A g A u S i O}_{2}-\mathbf{M T Z}$, there could be a combination of these interactions. In addition, the following catalytic studies agree with the interaction proposed since due to the lower catalytic activity of $\mathbf{A g S i O}_{2}-\mathbf{M T Z}$.

FTIR analyses were also carried out (shown in ESI†) but didn't show any evident differences, probably due to the low degree of functionalization and also to the known low intensity of the bands of imidazole and thiol moieties. The MTZ molecule is only detected by Raman spectroscopy as a result of the SERS effect. Due to the low amount of metal ( $\sim 1 \%$ in mass) and given

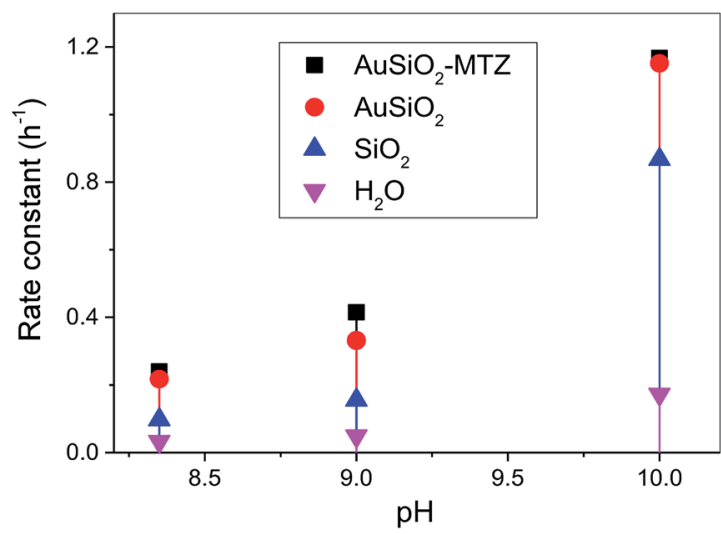

Fig. $6 \mathrm{pH}$ effect rate constant for the reaction of Au-derived NPs with DEDNPP at $20{ }^{\circ} \mathrm{C}$. Reaction with $\mathrm{SiO}_{2}$ and in water is shown for comparison. ${ }^{42}$

that the MTZ is anchored solely on the nanoparticle, the overall amount of MTZ is extremely low to detect or differentiate by FTIR.

\section{Catalytic activity on the detoxification of OP}

The catalytic activity of the MTZ-derived materials was evaluated in the cleavage reactions of $\mathbf{O P}$, thus its detoxification. Firstly, as a proof-of-concept, we choose one class of material, derived from $\mathrm{Au}$, to react with the model $\mathbf{O P}$ (i.e. simulant) DEDNPP. This is a common strategy before applying with real life $\mathbf{O P}$ due to their higher toxicity. In addition, DEDNPP is more reactive than Paraoxon, hence its reaction can be followed on a shorter time scale. Upon confirmation of the catalytic activity with DEDNPP, the nanocatalysts are then evaluated in the reaction with Paraoxon. Fig. 6 presents the rate constants at different $\mathrm{pH}$ values for the cleavage of DEDNPP with $\mathbf{A u S i O}_{2^{-}}$ derived catalysts. Constants solely with $\mathrm{SiO}_{2}$ under the same conditions is also shown along with the reaction in water (spontaneous). ${ }^{42,43}$

Firstly, it should be noted that reactions with solely MTZ is not shown, since its comparison is not straightforward because of its homogenous reaction nature (herein is heterogeneous) and to the difficulty of estimating the amount of MTZ coating the NPs. Therefore we cannot obtain the rate constant of pure MTZ in the same concentration coating the NPs, hence would lead to erroneous underestimated comparison. In addition, we could not evaluate the reactions of bare NPs since they aggregate. Results show that $\mathbf{A u S i O}_{2}-\mathbf{M T Z}$ is, in fact, effective in cleaving DEDNPP, specially at $\mathrm{pH}$ 9.0, since it differentiates from the non-coated material $\left(\mathbf{A u S i O}_{2}\right)$. At lower $\mathrm{pH}$, the MTZderived material shouldn't exhibit any activity due to the lower reactivity of imidazole moiety. ${ }^{42}$ On the other hand, at $\mathrm{pH} 10$, the reaction is very effective in all cases due to the contribution of the alkaline hydrolysis (reaction in water). Reactions solely with $\mathrm{SiO}_{2}$ evidenced for $\mathrm{pH} 8$ and 9, similar constants to the spontaneous reaction, although at $\mathrm{pH} 10$, its higher activity can be attributed to hydroxide species on the surface..$^{44}$ Insofar, the $\mathrm{pH}$ of interest to carry out further studies with the pesticide was 
Table 1 Rate constants for the cleavage reaction of Paraoxon with the nanocatalysts $^{a}$

\begin{tabular}{lc}
\hline & Rate constant, $\mathrm{g}^{-1} \mathrm{~h}^{-1}$ \\
\hline AgAuSiO $_{2}$ & \\
AgSiO $_{2}$ & 4.10 \\
$\mathrm{AuSiO}_{2}$ & 4.03 \\
$\mathrm{AgAuSiO}_{2}-\mathbf{M T Z}$ & 4.58 \\
$\mathrm{AgSiO}_{2}-\mathbf{M T Z}$ & 13.10 \\
AuSiO $_{2}-\mathbf{M T Z}$ & 3.76 \\
& 9.52
\end{tabular}

${ }^{a} \mathrm{pH} 9.0,20^{\circ} \mathrm{C}$. Rate constants are given as a function of the mass of metal in the nanocatalysts. Reactions solely with $\mathrm{SiO}_{2}$, where similar to the analogous spontaneous reaction at $\mathrm{pH}$ 9.0.

9.0, since the MTZ-derived material showed higher reactivity (although discrete) than their non-functionalized analogous.

Considering the positive results with DEDNPP, the nanocatalysts were then evaluated in the reactions with the highly toxic pesticide Paraoxon at $\mathrm{pH}$ 9. Table 1 presents the rate constants obtained given as a function of the mass of metal for the reactions of Paraoxon with all the materials: coated and non-coated with MTZ. In general, catalytic rate constants are given as a function of the reactive group of the catalysts, although in this case, it was not possible to calculate the concentration of MTZ in the materials obtained, low values are expected. One approach is to obtain the ratio of the rate constants and the total amount of catalysts, but since in the present study it was impregnated with $\mathrm{SiO}_{2}$, we found more convenient to consider the amount of metal that is responsible for interacting with the MTZ molecules. Nevertheless, not all NPs surface may be covered by MTZ, hence the rate constant considering solely the amount of MTZ reacting should be even higher. Overall, Table 1 evidences high rate constants for Paraoxon were among the highest reported in the literature. For example, previous studies with thiol-based nanocatalysts derived from graphene oxide show rate constants of $2.13 \mathrm{~g}^{-1}$ $\mathrm{h}^{-1}$ (considering the amount of the reactive group thiolate) with Paraoxon. ${ }^{10}$ In another study, Ag, and cobalt (Co) NPs were coated with imidazole derived fatty acids that give rate constants for Co-derived material $\sim 1.3 \mathrm{~g}^{-1} \mathrm{~h}^{-1}$ (considering the amount of metal). ${ }^{16}$ A magnetic nanocatalyst of iron oxide with supported amino acids (Asp-His) was also used to cleave Paraoxon with a rate constant of $0.30 \mathrm{~g}^{-1} \mathrm{~h}^{-1}$ (considering the amount of $\mathrm{Fe}_{2} \mathrm{O}_{3}$-Asp-His). ${ }^{18}$

While only discrete enhancements were observed for the MTZ-derived materials towards DEDNPP in comparison to its non-functionalized material, the difference was substantially different with Paraoxon (for Au- and AgAu-based materials). This is not unprecedented since Paraoxon is much less reactive than DEDNPP. In fact, as mentioned, DEDNPP is a simulant of OP such as Paraoxon and is used to verify possible catalytic effects, since the response is fast.

A more detailed analysis of Table 1 shows that upon functionalization of $\mathbf{A u S i O}_{2}$ with $\mathbf{M T Z}$, the rate constant nearly doubles. In the case of $\mathbf{A g A u S i O}{ }_{2}$, the analogous MTZ nanocatalyst increases more significantly the rate constant. In

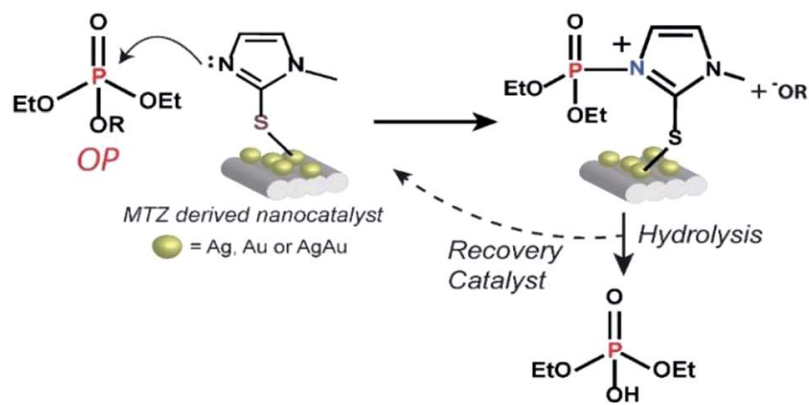

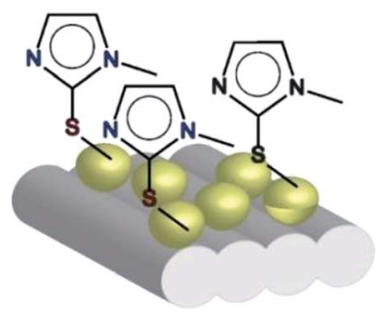

$\mathrm{AuSiO}_{2}-\mathrm{MTZ}$

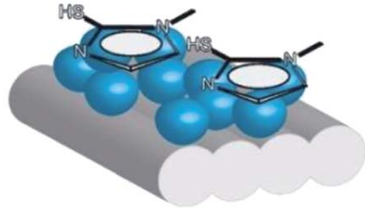

$\mathrm{AgSiO}_{2}-\mathrm{MTZ}$
Fig. 7 The mechanism proposed for the reaction of the OP with the nanocatalysts and interaction of MTZ with $\mathrm{Au}$ and $\mathrm{Ag}$-derived materials.

contrast, with $\mathbf{A g S i O}_{2}$, functionalization slightly decreases the rate constant. This behavior agrees with previous Raman analyses that indicate that for Ag-derived materials, MTZ interacts via the nitrogen while Au-based materials prefer the sulfur atom. Hence, the effect of MTZ on Au- and AgAu-based nanocatalysts is different from that of Ag-based materials. This can be explained by the expected mechanism for reactions of imidazole with OP, shown in Fig. 7. Based on previous mechanistic studies, ${ }^{45}$ the nitrogen of the imidazole ring attacks the phosphorus atom, thus cleaving the OP and leading to a phosphorylated intermediate and the phenolic product -OR. In the following, the unstable intermediate is hydrolyzed giving inorganic phosphate and regenerating the MTZ-derived nanocatalyst. This mechanism has been broadly accepted for imidazole mediated reactions and occurs analogously in many enzymatic active sites, therefore the nanocatalysts can be considered as artificial enzymes. Further, the proposed mechanism is consistent with the recycling of the nanocatalyst. Indeed, the UV-vis spectra taken after the reactions don't show any lixiviation of MTZ or the NPs, since the only band that appears in solution is of the products.

Correlating the mechanism with the proposed interaction for $\mathbf{A u S i O}_{2}-\mathbf{M T Z}$ (or $\mathbf{A g A u S i O}{ }_{2}-\mathbf{M T Z}$ ) and $\mathbf{A g S i O}{ }_{2}-\mathbf{M T Z}$ (vide Raman), we can observe that, while $\mathrm{Au}-\mathrm{S}$ guarantees freely available imidazole groups, Ag-N, doesn't (shown in Fig. 7). Therefore, $\mathbf{A g S i O}_{2}-\mathbf{M T Z}$ doesn't exhibit significant catalytic activity in contrast to $\mathbf{A u S i O}_{2}$ due to the type of interaction that directly disables the mechanistic preference.

Regarding the catalytic activity for the NPs without MTZ, this can be attributed to the Lewis acidity of the metal which interacts favorably with the phosphoryl oxygen, leading to a more electrophilic phosphorus center, as observed for ester cleavage (phosphate or acyl). ${ }^{\mathbf{1 5 , 1 6}}$ 


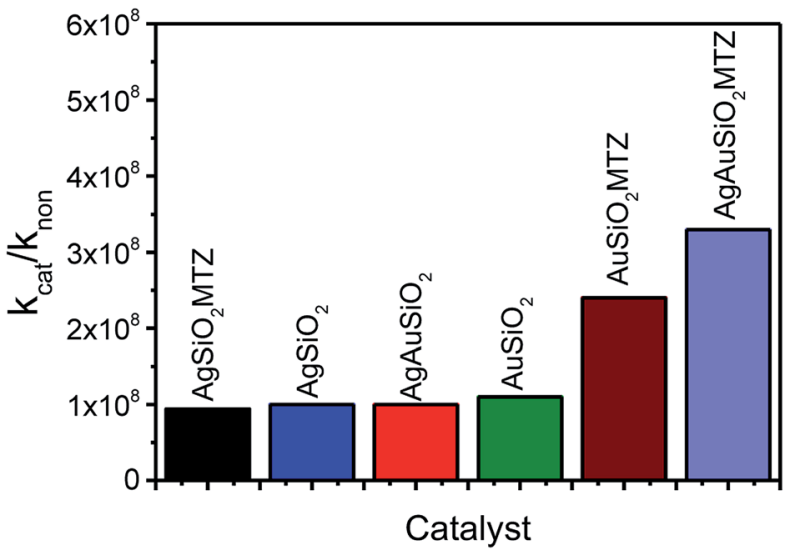

Fig. 8 Rate enhancements of the nanocatalysts with Paraoxon ( $k_{\text {cat }}$ in $\left.\mathrm{g}^{-1} \mathrm{~h}^{-1}\right)$ compared to the reaction with water $\left(k_{\mathrm{H}_{2} \mathrm{O}}\right.$ in $\left.\mathrm{g}^{-1} \mathrm{~h}^{-1}\right) \cdot{ }^{45}$

Fig. 8 presents the rate enhancements of the nanocatalysts with Paraoxon when compared to its spontaneous reactions $\left(k_{\mathrm{H}_{2} \mathrm{O}}=1.20 \times 10^{-7} \mathrm{~h}^{-1}\right.$ or $\left.4.0 \times 10^{-8} \mathrm{~g}^{-1} \mathrm{~h}^{-1}\right),{ }^{45}$ evidencing that the materials proposed are highly reactive towards OP detoxification. Interestingly, $\mathbf{A g A u S i O} \mathbf{S}_{2}-\mathbf{M T Z}$ is the most efficient nanocatalyst. This could be related to another previous study that concluded that bimetallic AgAu NPs (without $\mathrm{SiO}_{2}$ ) are better catalysts toward 4-nitrophenol reduction than $\mathrm{Au}$ or $\mathrm{Ag}$ NPs. This effect was attributed to a possible higher surface area, resulting from the formation of porous/hollow walls. ${ }^{25}$

\section{Conclusions}

Herein, we functionalized $\mathrm{Ag}$, $\mathrm{Au}$ and bimetallic AgAu NPs (supported on $\mathrm{SiO}_{2}$ ) with $\mathbf{M T Z}$, in order to obtain nanocatalysts comprising freely available imidazole groups. Results evidence that the NPs were successfully coated and that MTZ interacts preferably via sulfur atom over Au NPs and via the imidazole nitrogen over Ag NPs. The nanocatalysts were highly effective towards OP cleavage. For example, Fig. 9 illustrates the efficiency of detoxification of the toxic OP Paraoxon with the nanocatalysts, that is given as the time in days taken to degrade $50 \%$ of the OP. Normally in water, the lifetime of Paraoxon is extremely high and the estimated time to degrade $50 \%$ is over 600 years. ${ }^{45}$ In the presence of the nanocatalysts, this time is reduced to 7 days with the most reactive $\mathbf{A g A u S i O}_{2}-\mathbf{M T Z}$.

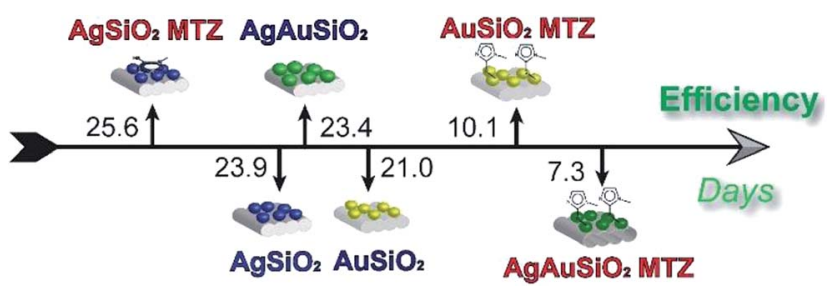

Fig. 9 Efficiency for the detoxification of Paraoxon by the nanocatalysts, given as the time in days required to degrade $50 \%$.
The higher activity of Au-derived nanocatalysts was attributed to the imidazole group that is free to react with the $\mathbf{O P}$, since in this case $\mathrm{Au}-\mathrm{S}$ interactions is preferable. When $\mathrm{Ag}-\mathrm{N}$ interactions takes place, the reactivity of imidazole is reduced.

Overall, we were able to detoxify OP efficiently which is promising destroying toxic stocks and also to design monitoring devices for these compounds. These perspectives are aligned with the importance of the issue as evidenced by the Peace Nobel Prize in 2013 awarded by the Organization for the Prohibition of Chemical Weapons "for its extensive efforts to eliminate chemical weapons". ${ }^{46}$

\section{Conflicts of interest}

There are no conflicts to declare.

\section{Acknowledgements}

Authors acknowledge the financial support from UFPR, CNPq, CAPES, Fundação Araucária, L'Oréal-UNESCO-ABC National, Institute of Science and Technology of Carbon Nanomaterials (INCT-Nanocarbon).

\section{References}

1 S. C. L. Kamerlin, P. K. Sharma, R. B. Prasad and A. Warshel, Q. Rev. Biophys., 2013, 46, 1-132.

2 F. H. Westheimer, Science, 1987, 235, 1173-1178.

3 A. J. Kirby, B. S. Souza and F. Nome, Can. J. Chem., 2015, 93, 422-427.

4 S. C. Kamerlin, P. K. Sharma, R. B. Prasad and A. Warshel, Q. Rev. Biophys., 2013, 46, 1.

5 K. Kim, O. G. Tsay, D. A. Atwood and D. G. Churchill, Chem. Rev., 2011, 111, 5345-5403.

6 Y. C. Yang, J. A. Baker and J. R. Ward, Chem. Rev., 1992, 92, 1729-1743.

7 R. T. Delfino, T. S. Ribeiro and J. D. Figueroa-Villar, J. Braz. Chem. Soc., 2009, 20, 407-428.

8 A. M. Manfredi, W. Demos, E. H. Wanderlind, B. V. Silva, A. C. Pinto, B. S. Souza and F. Nome, J. Phys. Org. Chem., 2016, 29, 600-603.

9 E. S. Orth, J. E. S. Fonsaca, T. G. Almeida, S. H. Domingues, J. G. L. Ferreira and A. J. G. Zarbin, Chem. Commun., 2014, 50, 9891-9894.

10 J. Fonsaca, L. Hostert, E. S. Orth and A. J. Zarbin, J. Mater. Chem. A, 2017, 5, 9591-9603.

11 P. V. Attwood, M. J. Piggott, X. L. Zu and P. G. Besant, Amino Acids, 2007, 32, 145-156.

$12 \mathrm{~K}$. Hofmann, Imidazole and its derivatives, Interscience Publishers, New York, 1953.

13 J. G. Ferreira and E. S. Orth, J. Braz. Chem. Soc., 2017, 28, 1760-1767.

14 P. Xu, S. Guo, H. Yu and X. Li, Small, 2014, 10, 2404-2412. 15 M. H. Kuchma, C. B. Komanski, J. Colon, A. Teblum, A. E. Masunov, B. Alvarado, S. Babu, S. Seal, J. Summy and C. H. Baker, Nanomedicine, 2010, 6, 738-744. 
16 L. Bromberg, L. Chen, E. P. Chang, S. Wang and T. A. Hatton, Chem. Mater., 2010, 22, 5383-5391.

17 L. Bromberg and T. A. Hatton, Ind. Eng. Chem. Res., 2007, 46, 3296-3303.

18 Y. Zheng, C. Duanmu and Y. Gao, Org. Lett., 2006, 8, 32153217.

19 L. Y. Kuo, A. K. Bentley, Y. A. Shari'ati and C. P. Smith, Organometallics, 2012, 31, 5294-5301.

20 L. Pasquato, F. Rancan, P. Scrimin, F. Mancin and C. Frigeri, Chem. Commun., 2000, 2253-2254.

21 L. Rassaei, F. Marken, M. Sillanpää, M. Amiri, C. M. Cirtiu and M. Sillanpää, TrAC, Trends Anal. Chem., 2011, 30, 1704-1715.

22 J. Zeng, Q. Zhang, J. Chen and Y. Xia, Nano Lett., 2009, 10, 30-35.

23 C. Jin, J. Han, F. Chu, X. Wang and R. Guo, Langmuir, 2017, 33, 4520-4527.

24 T. S. Rodrigues, A. G. da Silva, A. B. de Moura, I. G. Freitas and P. H. Camargo, RSC Adv., 2016, 6, 62286-62290.

25 M. V. Petri, R. A. Ando and P. H. Camargo, Chem. Phys. Lett., 2012, 531, 188-192.

26 C. M. Kisukuri, D. J. Palmeira, T. S. Rodrigues, P. H. Camargo and L. H. Andrade, ChemCatChem, 2016, 8, 171-179.

27 P. Pengo, S. Polizzi, L. Pasquato and P. Scrimin, J. Am. Chem. Soc., 2005, 127, 1616-1617.

28 T. S. Rodrigues, A. H. da Silva, A. G. da Silva, D. G. Ceara, J. F. Gomes, J. M. Assaf and P. H. Camargo, Catal. Sci. Technol., 2016, 6, 2162-2170.

29 T. S. Rodrigues, A. G. da Silva, A. Macedo, B. W. Farini, R. d. S. Alves and P. H. Camargo, J. Mater. Sci., 2015, 50, 5620-5629.

30 A. G. da Silva, T. S. Rodrigues, A. Macedo, R. T. da Silva and P. H. Camargo, Quim. Nova, 2014, 37, 1716-1720.
31 G. N. Bowers, R. B. McComb, R. Christensen and R. Schaffer, Clin. Chem., 1980, 26, 724-729.

32 L. J. Daumann, L. Marty, G. Schenk and L. R. Gahan, Dalton Trans., 2013, 42, 9574-9584.

33 K. TekaiaáElhsissen, J. Mater. Chem., 1996, 6, 573-577.

34 Y. Sun, B. Mayers and Y. Xia, Adv. Mater., 2003, 15, 641-646. 35 M. Muniz-Miranda, F. Muniz-Miranda and A. Pedone, Phys. Chem. Chem. Phys., 2016, 18, 5974-5980.

36 N. Biswas, S. Thomas, A. Sarkar, T. Mukherjee and S. Kapoor, J. Phys. Chem. C, 2009, 113, 7091-7100.

37 D. De Faria, H. Gil and A. De Queiroz, J. Mol. Struct., 1999, 478, 93-98.

38 J. García-Aguilar, D. Cazorla-Amorós and Á. BerenguerMurcia, Appl. Catal., A, 2017, 538, 139-147.

39 T. A. Saleh, M. M. Al-Shalalfeh and A. A. Al-Saadi, Sci. Rep., 2016, 6, 32185.

40 B. Pergolese, M. Muniz-Miranda and A. Bigotto, J. Phys. Chem. B, 2004, 108, 5698-5702.

41 P. Galinetto, A. Taglietti, L. Pasotti, P. Pallavicini, G. Dacarro, E. Giulotto and M. Grandi, J. Appl. Spectrosc., 2016, 82, 10521059.

42 E. S. Orth, E. H. Wanderlind, M. Medeiros, P. S. M. Oliveira, B. G. Vaz, M. N. Eberlin, A. J. Kirby and F. Nome, J. Org. Chem., 2011, 76, 8003-8008.

43 E. H. Wanderlind, Cinética e mecanismo de hidrólise do triéster dietil 2,4-dinitrofenil fosfato, Master thesis, Federal University of Santa Catarina, 2014.

44 A. Torrents and A. T. Stone, Environ. Sci. Technol., 1991, 25, 143-149.

45 E. S. Orth, T. G. Almeida, V. B. Silva, A. R. M. Oliveira, F. M. M. Ocampos and A. Barison, J. Mol. Catal. A: Chem., 2015, 403, 93-98.

46 https://www.nobelprize.org/nobel_prizes/peace/laureates/ 2013/opcw-facts.html, accessed in May, 5, 2017. 